\title{
Пандемии и вооруженные силы: какие роли являются подходящими?
}

\section{Джон Л. Кларк}

Европейский центр исследований по вопросам безопасности им. Джорджа К. Маршалла, https://www.marshallcenter.org

\begin{abstract}
Резюме: В условиях нынешнего пандемического кризиса вооруженные силы многих стран призваны оказывать помощь и поддержку гражданским властям в постоянно расширяющемся диапазоне. В этой статье исследуются виды ролей, миссий, задач и функций, которые вооруженные силы выполняют в этом кризисе, и определяется ряд политических соображений, над которыми должны задуматься лица, принимающие решения, когда они рассматривают возможность поручить вооруженным силам предоставлять эти услуги.
\end{abstract}

Ключевые слова: кризисный менеджмент, поддержка гражданских властей со стороны вооруженных сил, бедствие, охрана правопорядка, способности, COVID-19

\section{Реакция вооруженных сил на пандемическую болезнь}

Кризис COVID-19 заставил лидеров всех пострадавших стран обратиться к своим вооруженным силам за поддержкой в постоянно расширяющемся диапазоне ролей. Вооруженным силам поручено обеспечить способности, которые во многих случаях выходят за рамки того, что они предоставляли в прошлые кризисы. Следует ожидать, что эти требования будут продолжать расти даже после того, как нынешний кризис утихнет, поскольку ожидается, что пандемия останется главной национальной проблемой в ближайшие месяцы. В этой статье исследуется ряд ролей, которые вооруженные силы взяли на себя в контексте этого кризиса, и эти роли, миссии, задачи и функции рассматриваются в схеме из шести наборов миссий, которые составляют категорию Поддержка гражданских властей оборонными структурами 
(ПГВОС). Далее в статье излагаются полдюжины соображений, которые лицам, принимающим решения, следует учитывать, прежде чем просить вооруженные силы взять на себя эти роли.

В нынешнем пандемическом кризисе многие задачи, присущие категории ПГВОС, были видны в требованиях политических лидеров о поддержке, оказываемой вооруженными силами, таких как предоставление основных сервисов (многие из которых логистические и медицинские по своему характеру), а также некоторых способности для поиска и инженерной поддержки. Например, вооруженные силы в Италии, Испании, Франции, Соединенных Штатах и в других странах строили и укомплектовывали медицинские учреждения, транспортировали пациентов с вирусом, доставляли продукты питания, обыскивали здания на предмет поиска жертв и дезинфицировали жилые помещения, офисы и общественные объекты, такие как вокзалы и аэропорты.

Кроме того, структуры вооруженных сил предоставляли похоронные услуги, включая транспортировку и кремацию останков жертв вируса, которые, конечно же, заражены. На фотографиях частей итальянской армии запечатлены колонны грузовиков с гробами. Военные также оказывали медицинскую помощь перегруженным больницам. Были сфотографированы военные, которые проводят тесты на вирус, перемещают пациентов по больницам и предоставляют базовые услуги, такие как смена унитазов и предоставление еды, - и все это в зараженной среде. Французские военные самолеты, оборудованные для медицинской эвакуации, доставляли пациентов с вирусом в менее нагруженные медицинские учреждения во Франции.

Конечно, военно-медицинские учреждения и военно-медицинский персонал оптимизированы не для пандемических вспышек, а для операций с травмами на поле боя. Кроме того, использование военных медицинских объектов и персонала для поддержки гражданских объектов неизбежно сказывается на способности военных оказывать медицинские услуги своим собственным силам.

По мере того, как общества подвергаются растущему - и неослабевающему - давлению из-за пандемического кризиса, политические лидеры все чаще обращаются к вооруженным силам пострадавших стран, чтобы получить поддержку для своей полиции и для сил безопасности, а также для испытывающих трудности медицинских организаций и организаций здравоохранения. Спектр ролей и задач, которые призван выполнять личный состав вооруженных сил, быстро расширяется, и это окажет значительное влияние на способность этих военных организаций выполнять свои основные задачи по мере усугубления кризиса, вызванного коронавирусом.

Во всех западных странах вооруженные силы имеют долгую и достойную уважения историю оказания поддержки гражданским властям в преодолении внутренних чрезвычайных ситуаций. Для многих стран, особенно в Европе, поддержка гражданских властей является основной миссией, равной 
по значению защите национальной безопасности; в других странах, особенно в Африке и Азии, в центре внимания национальных вооруженных сил находятся внутренние вопросы. Таким образом, традиция, что вооруженные силы оказывают поддержку гражданской власти, а в некоторых случаях даже подменяют ее, прочно укоренилась. В результате мы видим, что национальные власти все больше полагаются на вооруженные силы для решения нового круга общественных задач в ответ на кризис. Учитывая тенденции, существующие в современных обществах, стоит изучить, что политические лидеры и общества, которые они возглавляют, просят военных делать и к чему это может привести, поскольку требования к вооруженным силам будут только расти.

\section{Внутренние миссии}

Во внутреннем контексте существует два основных набора миссий: защита родины и гражданская поддержка. Защита отечества - это традиционная задача защиты населения, инфраструктуры и суверенитета нации от угроз, исходящих извне. Это может включать такие задачи, как защита границы (в отличие от пограничной безопасности), противовоздушная оборона и защита морских подходов.

Конечно, большинство вооруженных сил в странах НАТО были предназначены для выполнения миссии времен холодной войны по защите европейской родины в случае нападения Варшавского договора; их унаследованная устаревшая организация и оборудование свидетельствуют об этом. Например, у Германии было большое количество бронетанковых войск и большое количество резервных сил; оба вида сил почти исчезли в период после окончания холодной войны. Оставшиеся силы часто реорганизовывались, по большей части, для развертывания за границей в операциях по поддержанию мира. Кроме того, их численность сократилась. У большинства стран НАТО есть действующие структуры вооруженных сил, которые составляют лишь малую часть их численности в период холодной войны, поэтому возникает второй вопрос: остается ли защита родины основной задачей? И если да, могут ли европейские вооруженные силы действительно осуществить это, если понадобится? На какое-то время во многих европейских странах все еще сохраняется относительно большое количество солдат по должностному расписанию; однако, они не соответствующе организованы, настроены, обучены и оснащены для современных конвенциональных высокоинтенсивных операций.

Помимо обороны страны, вооруженные силы НАТО всегда принимали активное участие во второй миссии внутри страны - оказание поддержки гражданскому населению и гражданским властям. Задачи гражданской поддержки - это те, которые выполняются в поддержку гражданской власти, при этом ответственность и общее руководство остаются за этой гражданской властью. Эти задачи включают в себя помощь местным властям в 
случае стихийных бедствий, а также поддержку правоохранительных органов при выполнении некоторых задач. Сюда также могут входить действия, предпринимаемые военными для восстановления законности, порядка и стабильности после крупной катастрофы или восстания. В таких операциях могут участвовать как активные, так и резервные силы, а также некоторые специализированные средства, такие как воздушные радиолокационные станции для наблюдения за границей. В любом случае главное - чтобы управление оставалось за гражданскими лицами.

Действительно, круг задач, для решения которых могут быть привлечены вооруженные силы, всегда был широким и продолжает расширяться. Военные силы во многих случаях стали предпочтительным ресурсом для многих политических лидеров, столкнувшихся с неразрешимыми (часто бюджетными) проблемами, в том числе многими не связанными с национальной безопасностью или гуманитарной помощью.

Ясно, что есть задачи гражданской безопасности, которые армии могут, должны и обязаны выполнять. В этой статье основное внимание уделяется определению тех внутренних ролей и задач, которые присущи национальным вооруженным силам, тех, для выполнения которых могут призвать вооруженные силы, и тех, которые являются кандидатами на включение в этот растущий список, с особым упором на роль вооруженных сил в обеспечении кибербезопасности. Но стоит поинтересоваться какие задачи армия не должна выполнять. Есть задачи, для решения которых военные силы по разным причинам не подходят. Это не означает, что вооруженные силы неспособны выполнять их, просто они не соответствуют тому, что мы можем считать приемлемыми задачами гражданской поддержки. Есть ли красные линии, за которые вооруженным силам не следует выходить?

Похоже, что существует шесть различных наборов миссий по поддержке гражданской власти (ПГВОС) для вооруженных сил в сфере гражданской безопасности, четыре из которых особенно полезны в период пандемических кризисов. Это:

- Поддержка, оказываемая оборонными структурами при чрезвычайных ситуациях и помощь при стихийных бедствиях (ПОСЧССБ);

- Поддержка, оказываемая оборонными структурами органам охраны правопорядка (ПОСООП);

- Поддержка, оказываемая оборонными структурами в случае особых событий (ПОСОС);

- Поддержка, оказываемая оборонными структурами для выполнения основных услуг (ПОСОУ);

- Поддержка, оказываемая оборонными структурами в борьбе с повстанцами (ПОСБП);

- Поддержка, оказываемая оборонными структурами в случае гражданских беспорядков (ПОСГБ). 
Четыре миссии, которые, очевидно, применимы для пандемических кризисов, это: Поддержка, оказываемая оборонными структурами при чрезвычайных ситуациях и помощь при стихийных бедствиях (ПОСЧССБ); органам охраны правопорядка (ПОСООП); для выполнения основных услуг (ПОСОУ); в случае гражданских беспорядков (ПОСГБ). Эти четыре миссии будут подробно рассмотрены в плане их реализации в случае пандемических кризисов.

Вооруженные силы Северной Америки и Европы уже давно выполняют такого рода миссии. Обычно и ожидается, что в чрезвычайных ситуациях в стране, вооруженные силы страны отреагируют и окажут надежную поддержку. Военные ожидают, что их вызовут для оказания помощи в подобных чрезвычайных ситуациях, и они могут принести с собой уникальные способности, такие как способность работать в зараженной среде и обеспечивать собственную логистику и безопасность. Военные могут ожидать увеличения количества обращений гражданских властей к их услугам. Конкретные роли, задачи, миссия и функции, которые, как ожидается, будут выполнять военные организации, формируют набор требований, требующих таксономии, четко определяющей категории ожидаемых задач.

\section{Поддержка, оказываемая оборонными структурами при чрез- вычайных ситуациях и помощь при стихийных бедствиях}

Когда случаются серьезные чрезвычайные ситуации, в число первых реагирующих почти всегда входят военные. В мире сложных чрезвычайных ситуаций вооруженные силы обеспечивают уровень способностей, который почти всегда востребован с самого начала кризиса. Военные силы могут действовать быстрее и часто более комплексно, чем обычно гораздо меньшие гражданские структуры реагирования на чрезвычайные ситуации. Вооруженные силы часто обладают уникальными возможностями для борьбы с конкретными видами чрезвычайных ситуаций, такими как разливы токсичных химикатов, которых часто не хватает этим другим силам реагирования. Поэтому неудивительно, что многие вооруженные силы считают реагирование на внутренние чрезвычайные ситуации и бедствия одной из своих основных задач. Вооруженные силы проявляют исключительную активность в реакции на запросы гражданского руководства о помощи в подобных чрезвычайных ситуациях.

Вооруженные силы обладают рядом характеристик, которые позволяют быстро, четко и эффективно реагировать на чрезвычайные ситуации и бедствия. Возможно, самая важная способность, которую вооруженные силы могут предложить гражданскому руководству в случае катастроф, - это самая элементарная: способность обеспечивать себя. Хотя эта возможность элементарна, она часто имеет решающее значение, особенно на ранних стадиях подобных катастроф. Способность вооруженных сил к самостоятельному развертыванию и самообеспечению может иметь решающее значение. У вооруженных сил есть свои собственные механизмы материально- 
технического обеспечения, в частности, в отношении транспорта, жилья и средств к существованию, а также собственные медицинские возможности. Большое значение имеет способность военных обеспечивать свою безопасность, а также предоставлять ее другим организациям. Тот факт, что многие воинские части находятся в состоянии готовности, также способствует способности реагировать своевременно. Таким образом, военные обладают уникальной способностью реагировать и обеспечивать ключевые способности в случае чрезвычайных ситуаций и катастроф.

Типичные задачи воинских частей при реагировании на чрезвычайные ситуации и оказании помощи в случае стихийных бедствий включают оказание основных услуг пострадавшему населению. В случае серьезной катастрофы может пострадать снабжение такими вещами первой необходимости, как вода и еда, а также обеспечение жильем и медицинской помощью. Военные - с их способностью быстро доставлять гуманитарную помощь в пострадавший район - часто являются единственной организацией, способной обеспечить это в масштабах, необходимых для оказания помощи. Кроме того, воинские части могут использоваться для поддержки, когда нужно много человеческой силы, такой как поиск и спасение при землетрясениях, при борьбе с наводнениями, что может включать заполнение и установку барьеров из мешков с песком, инженерное обеспечение, которое может включать производство и транспортировку энергии, обеспечение работы коммунальных служб и очистки воды, а также ремонт поврежденной транспортной инфраструктуры, такой как мосты и дороги. Это возможности, которые не часто имеются в гражданских организациях по менеджменту чрезвычайных ситуаций в количестве, достаточном для реагирования при крупных бедствиях.

Другие военные меры реагирования на стихийные бедствия и чрезвычайные ситуации могут включать узкоспециализированные способности, которые могут вообще отсутствовать в гражданских организациях. Сюда могут входить специализированные средства связи, в том числе лингвистическая поддержка, для предоставления общественной информации во время бедствий, похоронные услуги для надлежащего захоронения человеческих останков, управление воздушным движением и портовые услуги, которые часто необходимы для оказания помощи при бедствиях. Вооруженные силы также способны обеспечивать командование и управление, что часто имеет решающее значение для организации и развертывания последующей поддержки. Системы управления часто оказываются неэффективными на ранних стадиях бедствия, а во многих общинах отсутствуют резервные средства управления и контроля, которые могут предоставить военные.

Как мы видели, вооруженные силы почти всех стран мира активно участвовали в реагировании на чрезвычайную ситуацию, связанную с COVID-19. Действительно, спрос на военных и уникальные способности, которыми об- 
ладают вооруженные силы, продолжает расти; мы можем ожидать, что военные организации будут продолжать участвовать еще долгое время и что роли, которые они будут играть, будут продолжать расширяться.

\section{Поддержка, оказываемая оборонными структурами органам охраны правопорядка (ПОСООП)}

Военнослужащие не полицейские. Тем не менее, вооруженные силы традиционно оказывали помощь правоохранительным органам - деятельность, значение которой, похоже, становится все более важным, особенно в ответ на требования во время пандемических заболеваний.

Вооруженные силы оказывают поддержку правоохранительным органам двумя способами: первый - это поддержка, которая помогает правоохранительным органам лучше выполнять свою работу, предоставляя им технологии, обучение или материально-техническую поддержку, которая позволяет им более эффективно и действенно обеспечивать соблюдение закона. Второй вид поддержки, которую военные оказывают полицейским, - это их замена. Это предполагает использование военных вместо полицейских, что позволяет сотрудникам правоохранительных органов выполнять другие задачи.

Во-первых, вооруженные силы, благодаря наличию значительного количества высокотехнологичного оборудования и связанной с ним подготовки, могут предложить правоохранительным органам доступ к способностям, которые многие агентства обычно не имеют возможность использовать. Например, правоохранительные органы, отвечающие за безопасность границ, часто могут полагаться на радары наземного наблюдения, предоставленные военными. Точно так же вооруженные силы могут предоставлять авиационные средства, особенно вертолеты, в распоряжение правоохранительных органов, которые имеют ограниченные способности для воздушной мобильности.

В области обучения вооруженные силы часто могут обеспечить высокоспециализированную подготовку сотрудников правоохранительных органов. Примером может служить обучение работе с химическими и биологическими веществами и работе в загрязненной окружающей среде.

Военным также может быть поручено обеспечивать безопасность сотрудников полиции. Точно так же, как полицию часто просят помочь в обеспечении безопасности служб быстрого реагирования, действующих в сложных или небезопасных условиях, военных могут просить обеспечить определенную безопасность правоохранительным организациям, которым поручено осуществлять деятельность правоохранительных органов в таких районах, как городские трущобы и труднопроходимые местности, используемые организованной преступностью для того, чтобы скрывать свою деятельность. 
Во всех этих действиях ПОСООП военные должны быть, и это должно быть видно, как оказывающие поддержку гражданским правоохранительным органам. В тех случаях, когда вооруженные силы оказывают поддержку полицейским, всегда существует опасность чрезмерной милитаризации правоохранительных органов. Военные должны быть очень осторожны и избегать взятия на себя таких операций, если это не является явным намерением руководства страны.

Второй вид операции ПОСООП - это когда военные выполняют функции правоохранительных органов вместо полицейских. Скорее всего, это будут моменты, когда полицейские силы напряжены до предела и запрашивают поддержку вооруженных сил для выполнения конкретных задач правоохранительных органов в течение определенного периода. Например, вооруженные силы могут заменить полицию в выполнении функций низкого уровня по охране периметра или по управлению дорожным движением при обеспечении крупного спортивного мероприятия. Точно так же вооруженные силы могут проводить патрулирование в рамках усилий по обеспечению безопасности для защиты критически важной инфраструктуры или критических активов.

На военные подразделения также возложена ответственность за защиту некоторых критических объектов инфраструктуры и других ключевых объектов. Во Франции французские солдаты помогают защищать ключевые транспортные узлы, туристические достопримечательности, такие как Эйфелева башня, и некоторые звенья системы ядерной энергетики. В Италии вооруженные силы теперь обеспечивают внешнюю безопасность дипломатических представительств в Риме, освобождая полицию от этой задачи. Они также проводят совместное патрулирование с полицией в определенных частях некоторых итальянских городов. Такие операции, предполагающие присутствие вооруженных военных в форме на улицах европейских городов в ходе так называемых операций по демонстрации присутствия, также участились в последние годы, особенно в ответ на террористические угрозы.

Задачи посоОП ставят ряд проблем как перед военными, так и перед гражданскими властями, которые ими руководят. Обращение к вооруженным силам с просьбой обеспечить эти функции чревато милитаризацией правоохранительных органов. Эта тенденция к усилению полицейских сил может усугубляться, когда военные выполняют полицейские задачи.

Правовые аспекты тоже являются весьма спорными. Некоторые европейские страны, особенно Германия, запрещают использование военных для выполнения задач ПОСООП. Другие, такие как Франция и Италия, активно их используют. Однако юридические препятствия значительны. Последствия, связанные с разрешением военному персоналу применять силу, особенно смертоносную силу, для поддержки правоохранительной деятельности, весьма опасны. Солдат учат применять силу в первую, а не в по- 
следнюю очередь - в отличие от полицейской подготовки. Полномочие осуществлять аресты - еще одна проблемная сфера. В некоторых операциях ПОСООП может потребоваться разрешение солдатам арестовывать и задерживать подозреваемых; но это может привести к юридической ответственности солдат, если их полномочия четко не установлены законом.

Наконец, следует отметить, что присутствие военизированных полицейских сил, таких как французская жандармерия, итальянские карабинеры и испанская гражданская гвардия, снижает потребность в некоторых действиях ПОСООП в некоторых европейских странах. Часто эти гибридные силы способны удовлетворить многим из требований по ПОсООП. Универсальность этих сил позволяет решать широкий круг задач ПОСГВ.

Вооруженных сил просят взять на себя множество задач ПОсООП в ответ на текущий кризис. Все чаще военные освобождают перегруженные полицейские силы при выполнении задач правоохранительных органов низкого уровня, таких как контроль дорожного движения и обеспечение безопасности за пределами крупных городов, а также усиление сил пограничной безопасности. По мере развития ситуации вооруженным силам некоторых стран может потребоваться взять на себя дополнительные задачи по обеспечению безопасности, такие как обеспечение безопасности в тюрьмах и обеспечение продовольствием.

\section{Поддержка, оказываемая оборонными структурами для выпол- нения основных услуг (ПОСОУ)}

К военным часто обращаются для оказания услуг населению, когда по ряду причин эти услуги не могут быть предоставлены другими или потому, что эти услуги традиционно оказывали военные. Гражданские власти во многих странах без колебаний обращаются к своим вооруженным силам с просьбой о помощи, чтобы обеспечить предоставление услуг, которые они рассматривают как основные.

Под основными услугами мы подразумеваем те услуги, выполнение которых настолько важно для функционирования государства, что они должны быть предоставлены, иначе государство и его граждане пострадают, иногда очень тяжело. Примерами основных услуг могут быть услуги, связанные с реагированием на чрезвычайные ситуации: правоохранительные, пожарные и скорая помощь. Поскольку четкого определения не существует, государства стали свободно характеризовать услуги как важные, часто из-за потенциальных политических последствий отказа от их предоставления. В некоторых случаях эти услуги обычно оказывались другими структурами государства или коммерческими поставщиками.

Требование о предоставлении таких услуг может появляться по разным причинам. Они могут потребоваться, потому что крупная катастрофа сделала их обычного поставщика неспособным их обеспечивать, или промышленная авария или забастовка могли вызвать прекращение оказания кон- 
кретной услуги. Военные традиционно оказывали государству другие важные услуги, такие как обезвреживание взрывоопасных боеприпасов. Наконец, могут потребоваться специализированные одноразовые услуги, когда ни одно существующее государственное учреждение не может справиться с задачей только своими собственными ресурсами.

Список основных услуг, которые военные силы предоставляют гражданским властям, обширен. Операции ПОСОУ могут потребовать от военных оказывать самую разную поддержку, начиная от сбора мусора и заканчивая действиями от имени правительства в экстремальных обстоятельствах. В этом последнем случае вооруженные силы, в силу присущих им способностей по командованию и управлению, должны быть готовы к осуществлению функций по обеспечению непрерывности государственного управления (НГУ) и непрерывности операций (НО) в случае нарушения способности правительства функционировать, например из-за крупной природной катастрофы или из-за нападения.

Другие задачи ПОСОУ могут включать поисково-спасательные операции (ПСО). Во многих странах, таких как Финляндия, национальные службы ПСО находятся в вооруженных силах. Военные силы часто имеют необходимое оборудование, такое как вертолеты, и необходимую подготовку для выполнения этой задачи. Другие типы задач ПОСОУ такого рода могут включать создание и обслуживание лагерей для беженцев в случае массовой иммиграции из-за конфликта или стихийных бедствий в соседних странах.

До сих пор наиболее распространенной причиной использования вооруженных сил в операциях ПОСОУ является реакция на забастовки. Военные силы неоднократно оказывали важные услуги, такие как реагирование на пожары в случае забастовки пожарных, в том числе несколько раз за последние два десятилетия в Великобритании, а в последнее время в Греции в 2010 году.

Вооруженные силы также оказали помощь ПОСОУ в ответ на забастовки транспортных рабочих во Франции в 1980-х годах, рабочих-перевозчиков топлива в Великобритании в 2000 году и Греции в 2010 году, а также в нескольких случаях оказывали поддержку правоохранительным органам в ответ на забастовки сотрудников тюрем.

Этот набор задач включает случаи, когда военным поручается предоставлять услуги, которые считаются важными по соображениям безопасности или по другим причинам, например в сфере общественного здравоохранения. Примеры могут включать предоставление услуг по управлению воздушным движением в случае забастовки или оказание вспомогательных услуг после вспышки пандемического заболевания, как в нынешнем случае с глобальной чрезвычайной ситуацией, связанной с COVID-19. Поскольку те, кто работает в критических секторах, таких как транспорт, пожарная безопасность и скорая помощь, могут стать недееспособными из-за болезни, логично, что вооруженных сил могут попросить вмешаться для оказания 
таких услуг. Точно так же, когда государства начинают оправляться от разрушительного воздействия болезни, вооруженные силы, вероятно, будут играть более активную роль в дезинфекции общественных мест и при мониторинге населения на предмет рисков для здоровья.

\section{Поддержка, оказываемая оборонными структурами в случае гражданских беспорядков (ПОСгБ)}

Государства могут в результате войны, восстания или стихийного бедствия, счесть необходимым установить охрану закона, порядка и стабильности с помощью иных средств, кроме обычных правоохранительных органов. Во время сильных волнений и беспорядков, гражданское руководство может обнаружить, что его правоохранительные органы перегружены и что необходимо призвать военных помочь восстановить и поддерживать порядок. Оказание поддержки оборонными структурами во время большого кризиса может потребовать введения военного положения. Военное положение означает необходимость задействовать вооруженные силы для выполнения основных функций правоохранительных органов, а также множества других важных услуг. В большинстве стран НАТО не было военного положения в послевоенный период, даже в тех, в которых были военные правительства, которые действовали в соответствии с существующими в то время законами. Военное положение выходит далеко за рамки этого: солдаты выполняют задачи, предназначенные для сотрудников полиции.

Хотя это маловероятно, но необходимость ввести военное положение может возникнуть после значительной природной или промышленной катастрофы, такой как чрезвычайная ситуация, связанная с пандемией, или в ответ на крупную террористическую атаку с применением оружия массового поражения. В таких случаях может произойти общий срыв соблюдения закона, порядка и стабильности, что сделает существующие правоохранительные организации неспособными выполнять свои обязанности. В таком случае вооруженным силам необходимо будет установить контроль, обычно путем объявления военного положения. Хотя эта концепция не закреплена во многих конституциях, базовая структура для ее реализации обычно присутствует, особенно в тех странах, где есть милитаризованные полицейские силы.

Как уже отмечалось, в случаях полного срыва функционирования государства от вооруженных сил вполне может потребоваться выполнение широкого круга основных функций. Еда, вода, жилье, одежда - список может показаться бесконечным. Часто вооруженные силы, как было описано выше, являются единственными организациями, способными реагировать из-за их присущих им логистических возможностей и способности к самостоятельному развертыванию. 


\section{Критерии для субъектов, принимающих решения}

Для эффективной оценки ситуаций, в которых вооруженные силы могут быть использованы во внутренних чрезвычайных ситуациях, особенно в чрезвычайных ситуациях, связанных с пандемическими заболеваниями, требуются логические и простые критерии. При рассмотрении запросов о помощи следует учитывать шесть соображений. Конечно, считается, что в некоторых странах иногда эти критерии могут не замечаться или игнорироваться, если угроза катастрофического заболевания, с которой сталкивается страна, достаточно велика.

Первое и главное соображение - это законность. Каждый запрос следует оценивать с точки зрения соответствия законам этого государства и его международным обязательствам. Соответствуют ли запрос и способ его подачи законам страны, в частности, конституции и тем законам, которые были приняты для регулирования использования вооруженных сил? В то время, как во многих государствах, таких как Германия и США, действуют законы, ограничивающие внутреннее использование вооруженных сил, в других, особенно во Франции, таких ограничений нет. Также могут быть исключительные события, такие как крупные катастрофы или вспышки очень заразных заболеваний, приводящие к срыву соблюдения закона и порядка, что может потребовать способностей, которые могут предоставить только военные, даже если такая работа противоречит архитектуре закона. Хотя этого еще не произошло в случае с кризисом COVID-19, такую возможность нельзя исключать, особенно в связи с ростом безработицы и затрудненным доступом к продуктам питания.

Второй критерий - летальность. Этот критерий рассматривает вопрос о том, может ли военным в рамках оказания поддержки потребоваться применить силу, особенно смертоносную. Как уже говорилось ранее в этой статье, вопрос применения силы во внутренних чрезвычайных ситуациях чреват опасностью. Летальность также рассматривает возможность того, что против тех вооруженных сил, которые участвуют в усилиях по ПОСГВ, может быть использована сила. Возможность применения силы может потребовать, чтобы вооруженные силы были обеспечены специальным оборудованием и специально обучены, а также были изданы соответствующие правила, регулирующие применение силы. Как правило, вооруженные силы, поддерживающие гражданские власти, всегда должны стремиться избегать применения смертоносной силы, за исключением чрезвычайных ситуаций. Тем не менее, обстоятельства могут потребовать участия в потенциально смертельных действиях в целях самообороны или для предотвращения большего вреда населению, как это может иметь место в случае вспышки очень заразной и смертельной эпидемии. Если возникнет необходимость в принудительном применении карантинных приказов, может возникнуть ситуация, когда станет необходимо применить силу со всеми последствиями такого решения, как отмечалось выше в обсуждении ПОсгБ. 
Риск - третий из критериев, регулирующих использование вооруженных сил в ПОСГВ. Хотя он подобен летальности, риск больше связан с безопасностью солдат в миссиях ПОСГВ. В частности, он направлен на оценку наличия повышенного риска для безопасности и здоровья тех военных, которые в процессе выполнения задания могут подвергаться воздействию вредных веществ, таких как биологические или химические токсины, или от которых требуются опасные действия, такие как спасение гражданского персонала или тушение крупных пожаров. Например, поддержка гражданских властей в нынешнем кризисе COVID-19 может подвергнуть солдат воздействию самого вируса; аналогичным образом, дезактивация территории с радиационным или химическим загрязнением представляет опасность для сил, выполняющих эту задачу. Риск также направлен на определение долгосрочного воздействия на военных как физического, так и психологического выполнения задач, которые могут быть тяжелыми, такими как сбор и захоронение тел большого количества погибших в результате крупного бедствия или пандемического заболевания. Размещение солдат на улицах в военной форме может дать ощущение повышенной безопасности, но может сделать их более уязвимыми к нападениям.

Готовность - это четвертый критерий, который должен управлять процессом рассмотрения вопроса о развертывании вооруженных сил в миссиях ПОСгВ. Вооруженные силы существуют для защиты нации от внешних угроз; в той мере, в какой они вовлечены в задачи ПОСГВ, они могут быть не в состоянии выполнять свои основные задачи по национальной обороне, поскольку всегда есть сопутствующие издержки, которые нужно платить. Для тех задач ПОСГВ, которые мало связаны с военными функциями, таких как, скажем, сбор мусора, и которые могут иметь длительный характер, может иметь место некоторая эрозия основных военных навыков, таких как танковая стрельба или артиллерийская огневая поддержка, что потребует времени, усилий и ресурсов для восстановления. Готовность также направлена на измерение сопутствующих издержек, связанных со способностью вооруженных сил выполнять другие военные функции и функции ПОСГВ. Если армия или ее части задействованы в задаче ПОСГВ, она может быть не в состоянии быть используемой для выполнения других задач в разумные сроки. В случае чрезвычайной ситуации, связанной с COVID-19, мы наблюдали случаи, когда готовность воинских частей или морских сил подвергалась негативному воздействию. Кризис вирусного заражения, вероятно, также негативно повлияет на способность вооруженных сил рекрутировать и обучать новых членов.

Пятое соображение при оценке запроса - это расходы. Вопрос о том, кто платит за участие военных в ПОСГВ, приобретает все большее значение. Многие миссии и задачи ПОСГВ могут потребовать значительных затрат ресурсов. В частности, когда военные оказывают помощь гражданским властям в ликвидации последствий стихийных бедствий после крупного стихийного бедствия, это может включать в себя затраты значительных сумм 
на поставки и транспортировку в дополнение к затратам на персонал. В странах Европы эти расходы в некоторых случаях несет само министерство обороны. В других случаях министерство обороны ожидает возмещения части или всех этих расходов министерством или агентством, которому оказывается помощь. Эти соображения должны быть учтены задолго до того, как возникнет необходимость в поддержке, оказываемой вооруженными силами.

В тех случаях, когда ожидается, что министерство обороны оплатит оказываемую поддержку, этот критерий должен также включать оценку воздействия на ассигнования, в рамках которых функционируют военные. Также могут быть обстоятельства, при которых военные получают возмещение за предоставленные услуги и материалы, которые они могут использовать для целей, отличных от их восстановления. В этих случаях военные вполне могут использовать деньги для возмещения расходов для приобретения недостающего оборудования или для проведения необходимого обучения. В случае чрезвычайной ситуации в стране, связанной с вирусным заражением, вопрос о стоимости может быть изначально спорным, но он обязательно возникнет снова, когда кризис затянется.

Последний критерий - это соответствие. Этот критерий направлен на ответ на вопрос о том, правильно ли, или общественность считает правильным, выполнение военными задач ПОСгВ. Этот вопрос связан с более широкой проблемой имиджа вооруженных сил. Соответствие также связано с вопросом о том, в интересах ли министерства обороны выполнение данной задачи. В случае оказания помощи при стихийных бедствиях военные почти всегда отвечают утвердительно. Однако есть случаи, особенно те, которые связаны с потенциальным применением смертоносной силы против граждан, что может рассматриваться военными как несоответствующее и наносящее ущерб имиджу вооруженных сил.

Хотя эти шесть критериев чаще всего определяют оценку военными просьбы о помощи, могут быть и другие, такие как рассмотрение того, имеют ли военные возможности с точки зрения количества военнослужащих или их подготовки, чтобы предоставить помощь. У вооруженных сил изза экспедиционных операций или других ангажементов может просто не хватать повышенных ресурсов для оказания поддержки.

Еще одно соображение - это вопрос о наличии уникальных способностей. Как правило, военных следует просить предоставить поддержку ПОСГВ только в том случае, если военные обладают уникальными способностями, не имеющимся по типу или требуемому количеству в других агентствах. Типичный пример включает предоставление поддержки дезактивации. у большинства других ведомств нет военных возможностей для обеззараживания химического или биологического заражения; поэтому в случае такого инцидента может оказаться целесообразным запросить военную поддержку, поскольку никакое другое агентство не может предоставить такую поддержку. 


\section{Заключение}

Должно быть ясно, что вооруженные силы представляют собой огромный потенциал, который лица, принимающие решения, должны учитывать в случае кризиса, связанного с пандемическими заболеваниями. Вооруженные силы обладают рядом способностей, многие из которых уникальны, что может существенно повлиять на способность государства пережить кризис, который мы сейчас наблюдаем в отношении COVID-19. Растущая тенденция к дальнейшему расширению невоенных функций вооруженных сил, хотя и имеет большое значение, не обходится без затрат, которые в какой-то момент необходимо учитывать.

Кажется очевидным, что мы, вероятно, увидим все больше военных на улицах, выполняющих критически важные задачи. Мы должны приветствовать способность и готовность военных делать это. Но об этом вкладе нельзя забывать, когда кризис пройдет.

\section{Отказ от ответственности}

Выраженные здесь взгляды являются исключительно взглядами автора и не отражают точку зрения Консорциума оборонных академий и институтов изучения безопасности ПрМ, участвующих организаций или редакторов Консорциума.

Издание Connections: The Quarterly Journal, том 19, 2020 осуществляется при поддержке правительства Соединенных Штатов.

\section{6 авторе}

Д-р Джон Л. Кларк - профессор Центра им. Маршалла в Гармише, Германия. Доктор Кларк признан ведущим экспертом по вопросу роли вооруженных сил в обеспечении внутренней безопасности, в частности, по вопросам кибербезопасности. Он разработал и провел множество курсов по проблемам национальной безопасности, кризисному управлению и операциям по обеспечению стабильности, а также разрабатывал основанные на сценариях учения и симуляции. Он возглавлял крупный исследовательский проект по европейским подходам к внутренней безопасности. Опубликовал несколько книг о роли вооруженных сил в чрезвычайных ситуациях внутри страны, в том числе What Should Armies Do? Armed Forces in Civil Security and Armies in Homeland Security: American and European Perspectives [ 4 mo deлать армии? Вооруженные силы в гражданской безопасности и армии в национальной безопасности: американская и европейская точки зрения]. В последнее время он работал старшим научным сотрудником в исследовательской программе им. Эйзенхауэра в Оборонном колледже НАТО в Риме в 2016-2017 годах, уделяя особое внимание операциям по кибербезопасности. 